\title{
Atributos físicos de um Latossolo Vermelho correlacionados linear e espacialmente com a consorciação de guandu com milheto
}

\author{
Rafael Montanari $^{1 *}$, Edmar Casarin Zambianco ${ }^{2}$ Adriany Rodrigues Corrêa ${ }^{3}$. Douglas Martins Pereira Pellin ${ }^{3}$, \\ Morel de Passos e Carvalho ${ }^{4}$, Flávio Carlos Dalchiavon 5
}

\section{RESUMO}

O sistema cultivo mínimo, por possibilitar pouca movimentação de solo, menor número de operações agrícolas sem incorporação dos resíduos vegetais, apresenta vantagens em razão do menor custo de preparo e da redução das perdas de solo e água. No ano agrícola de 2006/2007, na Fazenda de Ensino e Pesquisa da Faculdade de Engenharia de Ilha Solteira, SP, Brasil - FEIS/UNESP, situada nas condições do Cerrado Brasileiro, objetivou-se analisar a produtividade de massa de matéria seca da consorciação de forragem (guandu+milheto) (MSF), em função de atributos físicos do solo, tais como resistência à penetração (RP), umidade gravimétrica (UG), umidade volumétrica (UV) e densidade do solo (DS) nas profundidades de 0,0-0,10 m; 0,10-0,20 m e 0,20-0,30 m. Para tanto, foi instalado um ensaio, contendo 117 pontos amostrais, em um Latossolo Vermelho distroférrico, sob pivô central, numa área experimental de $1600 \mathrm{~m}^{2} \mathrm{sob}$ cultivo mínimo. A análise estatística constou de análise descritiva inicial dos atributos e análise das correlações lineares simples entre eles, e, finalmente, de análise geoestatística. Do ponto de vista da correlação espacial, o atributo que mais bem explica a produtividade de massa de matéria seca da consorciação é a densidade do solo na camada de 0,20-0,30 m, com uma correlação inversa, indicando que as espécies se desenvolvem bem em solos adensados.

Palavras-chave: adubação verde, cultivo mínimo, consórcio, Pennisetum glaucum L. Leek., Cajanus cajan L. Millsp.

\section{ABSTRACT}

\section{Physical attributes of an Oxisol linear and spatially correlated with millet + pigeonpea intercropping}

The minimum tillage system allows little soil movement, fewer farm operations without incorporation of crop residues, thus, it has advantages due to lower cost of preparation and the reduction of soil and water losses. This study aimed to analyze the yield of dry mass of intercropping forage (millet+pigeonpea-DM) as a function of soil physical characteristics in the crop year 2006/2007. The experiment was conducted in the Teaching and Research Farm of the Faculty of Engineering of Ilha Solteira, SP, Brazil, FEIS/UNESP, located in the Brazilian Cerrado conditions. Soil penetration resistance (PR), gravimetric moisture (GM), volumetric water content (VW) and bulk density (BD) at depths of 0 to $0.10 \mathrm{~m}, 00.10$ to $0.20 \mathrm{~m}$ and 0.20 to $0.30 \mathrm{~m}$ were determined. A trial consisting of 117 sampling points in an

\footnotetext{
Recebido para publicação em 19/10/2011 e aprovado em 15/02/2012

${ }^{1}$ Engenheiro Agrônomo, Professor Doutor. Universidade Estadual de Mato Grosso do Sul, Unidade Universitária de Aquidauana, Rodovia Aquidauana-UEMS, Km 12, 79200-000, Aquidauana, Mato Grosso do Sul, Brasil. rafamontana@uems.br. *Autor para correspondência.

Engenheiro Agrônomo. Mestrando em Agronomia, Escola Superior de Agricultura "Luiz de Queiróz" - USP, Av. Pádua Dias, 11, 13418-900, Piracicaba, São Paulo, Brasil. edmarcasazambi@hotmail.com

${ }^{3}$ Engenheiros Agrônomos. Mestrandos em Agronomia: Produção Vegetal, Universidade Estadual de Mato Grosso do Sul, Unidade Universitária de Aquidauana, Rodovia AquidauanaUEMS, Km 12, 79200-000, Aquidauana, Mato Grosso do Sul, Brasil. adriany@agronoma.eng.br, douglas.martins@agronomo.eng.br

${ }^{4}$ Engenheiro Agrônomo, Professor Doutor. Universidade Estadual Paulista "Júlio de Mesquita Filho" (UNESP), Campus de Ilha Solteira, Av. Brasil, 56, Centro, 15385-000, Ilha Solteira, São Paulo, Brasil. morel@agr.feis.unesp.br

${ }^{5}$ Engenheiro Agrônomo. Doutorando em Agronomia: Sistemas de Produção, Universidade Estadual Paulista "Júlio de Mesquita Filho" (UNESP), Campus de Ilha Solteira, Av. Brasil, 56, Centro, 15385-000, Ilha Solteira, São Paulo, Brasil. fcdalchiavon@unemat.com
} 
Oxisol under center pivot was carried out in an experimental area of $1600 \mathrm{~m}^{2}$ under minimum tillage. The results were initially evaluated by descriptive statistics of the attributes and simple linear correlations between them, and finally, by geostatistical analysis. The spatial correlations showed that the attribute that best explains the yield of dry mass of the intercropping species was the density of the soil layer from 0.20 to $0.30 \mathrm{~m}$, with an inverse correlation, indicating that the species grows well in dense soils.

Key words: green manure, minimum tillage, intercropping, Pennisetum glaucum (L) Leeke, Cajanus cajan (L.) Millsp.

\section{INTRODUÇÃO}

O milheto (Pennisetum glaucum (L) Leeke) tem sido usado em muitas regiões do mundo, como alternativa para solução do problema da escassez de forragem na época fria e seca do ano. Um de seus efeitos úteis é a cobertura do solo com massa de matéria seca, que exerce proteção contra intempéries, além de liberar quantidades consideráveis de nutrientes nas camadas superficiais do solo (Basso et al., 2011).

O feijão-guandu (Cajanus cajan (L) Millsp) é uma leguminosa bastante promissora como fonte não convencional de alimentos, inclusive de produtos farináceos, prestando-se, ainda, às utilizações como planta forrageira e como adubo verde e, algumas vezes, ao sombreamento temporário (Morton et al., 1982). Apresenta alto potencial de sobrevivência em solos degradados e tolera o estresse hídrico, por seu sistema radicular pivotante e vigoroso, que possibilita romper camadas adensadas ou compactadas do solo, denominadas "pé de arado", característica que lhe garantiu a denominação de "arado ou subsolador biológico"; também é tido como melhorador químico dos solos, pela produção de massa vegetal de elevado teor de nitrogênio, ou pela capacidade de extração de fósforo em profundidade, nos solos (Lupatini, 1996).

O sistema de cultivo mínimo, por possibilitar pouca movimentação de solo, menor número de operações e baixa incorporação dos resíduos vegetais, apresenta vantagens em relação aos sistemas tradicionais de mobilização, em função do menor custo de preparo e da redução das perdas de solo e água. Por outro lado, Dallmeyer (1994) afirmou que a redução da erosão é obtida pela existência dos resíduos culturais na superfície do solo, assim como pelo aumento da rugosidade superficial e da porosidade, melhorando, desse modo, a infiltração de água no seu perfil.

Na prática conservacionista da rotação de culturas, deve-se utilizar a adubação verde como forma de reduzir custos com adubos, realizar a melhoria da qualidade químico-física do solo e a proteção contra agentes climáticos, durante a entressafra. A palha também tem a qualidade de reduzir a variação térmica e aumentar a retenção de água no solo, nos períodos de estiagem (Andreotti et al., 2008).
A resistência do solo à penetração é um atributo físico relativamente fácil de ser medido e, de certa forma, de ser correlacionado com a densidade e a macroporosidade do solo. Para um mesmo solo, quanto maior a densidade, maior será a resistência à penetração e menor, a macroporosidade. Esta última constitui-se no principal espaço para o crescimento das raízes. No entanto, deve ser levado em conta que a resistência do solo à penetração é mais afetada pela variação dos conteúdos de sua umidade (Mercante et al., 2003).

A geoestatística é utilizada para o estudo da variabilidade espacial dos atributos do solo e da planta, tendo o semivariograma como elemento que atesta sua aplicabilidade. Seu uso requer a coleta previamente planejada de amostras, com a localização espacial exata de cada ponto amostral. Estudos geoestatísticos têm relatado a influência dos atributos do solo sobre o padrão e a distribuição espacial da produtividade vegetal. Assim, sabe-se que a planta atua de forma a responder, sobretudo, quando sua produtividade é analisada espacialmente, de forma positiva ou negativa, conforme o comportamento da variação dos atributos do solo (Montanari et al., 2011).

Diante do exposto, esta pesquisa, objetivou: a) analisar a variabilidade dos atributos estudados da planta e do solo; b) definir as correlações lineares e espaciais entre a produtividade da massa de matéria seca da consorciação de forragens com os atributos físicos do solo pesquisado; c) pesquisar, entre os atributos físicos estudados, aquele que melhor se apresente para explicar a variabilidade da produtividade da massa de matéria seca da consorciação de forragens.

\section{MATERIAL E MÉTODOS}

O experimento foi conduzido entre novembro de 2006 e fevereiro de 2007, na Fazenda de Ensino e Pesquisa da Faculdade de Engenharia de Ilha Solteira (FEIS/UNESP), município de Selvíria (MS), Mato Grosso do Sul, Brasil, situada entre as latitudes $20^{\circ} 18^{\prime} 05^{\prime \prime} \mathrm{S}$ e $20^{\circ} 18^{\prime} 28^{\prime \prime} \mathrm{S}$ e as longitudes $52^{\circ} 39^{\prime} 02^{\prime \prime} \mathrm{W}$ e $52^{\circ} 40^{\prime} 28^{\prime \prime} \mathrm{W}$, com precipitação média anual de $1300 \mathrm{~mm}$ e temperatura média anual 23,7 . O tipo climático é Aw, segundo Köppen, caracterizado como tropical úmido com estação chuvosa no verão e 
seca no inverno. O solo estudado foi um Latossolo Vermelho distroférrico típico muito argiloso (entre 55 e $65 \%$ de argila), A moderado, hipodistrófico, álico, caulinítico, férrico, epicompactado, muito profundo, moderadamente ácido (Embrapa, 2006). Durante o período de condução do experimento, a precipitação na região foi de $864,8 \mathrm{~mm}$, a temperatura média foi de $26,1^{\circ} \mathrm{C}$ e a umidade relativa média, de 63,8\% (UNESP, 2011).

Foram definidas as direções dos eixos cartesianos da malha de dados, numa área sob pivô central, estabelecida entre dois terraços. Assim, o eixo $x$ foi ordenado em nível e o eixo $y$ ficou no sentido do declive de $1 \%$. Desse modo, a malha ficou constituída de 117 pontos amostrais, distribuídos numa área de $1600 \mathrm{~m}^{2}$ (40 m x 40 m). O espaçamento utilizado entre os pontos na grande malha foi de $5 \mathrm{~m}$, enquanto, na malha de refinamento, foi de 1,67 m. Essa última foi locada com a finalidade de se detectarem alcances da dependência espacial para espaçamentos menores do que $5 \mathrm{~m}$.

A consorciação realizada foi com plantas de guandu (Cajanus cajan) e de milheto (Pennisetum glaucum), com a finalidade de produção de palha, sendo que a semeadura foi realizada no dia 22 de novembro de 2006, sucedendo feijão em área sob sistema cultivo mínimo, com escarificação realizada dois dias antes. A semeadura foi em linhas simples, com espaçamento de 0,16 m entre as culturas, com regulagem da densidade de semeadura de 15 sementes de guandu por metro de linha.

A colheita manual do atributo da planta foi realizada no dia 8 de fevereiro de 2007 (77 dias após semeadura), determinando-se a área útil de 0,4096 m² (0,64 x 0,64 m) por ponto, com locação do ponto da malha centralizado entre quatro linhas de cultivo, sendo este método baseado na menor distância entre dois pontos (1,67 m). Todas as plantas da área útil de cada ponto amostral (PA) foram retiradas, por meio de corte com cutelo, a aproximadamente de 5 a $7 \mathrm{~cm}$ do nível do solo, efetuando-se a pesagem para conhecimento da massa de matéria úmida total (MU). Posteriormente, para obtenção dos valores da massa de matéria seca da forragem (MSF), utilizou-se um fator de correção (FC), o qual representou a relação massa de matéria seca/verde para cada ponto amostral, sendo obtido da seguinte forma: foram trituradas 5 plantas de guandu e 5 plantas de milheto, escolhidas aleatoriamente, dentre todas as plantas coletadas na área útil do ponto amostral. A seguir, retirou-se uma pequena amostra, a qual foi pesada imediatamente (massa de matéria verde). Posteriormente, o material foi acondicionado em sacos de papel e levado para estufa com circulação forçada de ar, à temperatura de $65^{\circ} \mathrm{C}$, por 72 horas, até atingir massa constante, sendo pesado novamente (massa de matéria seca). Portanto, a expressão para o cálculo do atributo trabalhado da planta, (MSF), individualmente para cada ponto amostral, foi dada por:

$\mathrm{MSF}=(\mathrm{MU} / \mathrm{PA}) . \mathrm{FC} \cdot 10^{4}$

em que: MSF representou a produtividade da massa de matéria seca da forragem, num determinado ponto amostral $\left(\mathrm{kg} \mathrm{ha}^{-1}\right)$;

MU representou a massa de matéria úmida total das plantas contidas na área designada por tal ponto $(\mathrm{kg})$;

PA representou a área útil do ponto amostral $\left(\mathrm{m}^{2}\right)$;

FC representou o fator de correção da produtividade de massa de matéria verde para a produtividade de massa de matéria seca da forragem contida no ponto e $10^{4}$ foi o fator de conversão de $\mathrm{kg} \mathrm{m}^{-2}$ para kg ha-1 (Pariz et al., 2011).

As análises laboratoriais foram realizadas no laboratório do Departamento de Fitossanidade, Engenharia Rural e Solos da Faculdade de Ilha Solteira (UNESP). Os atributos do solo, coletados no dia 5 de março de 2007, ao redor do ponto amostral foram: umidade gravimétrica (UG), umidade volumétrica (UV) e resistência do solo à penetração (RP), nas profundidades de 0,0-0,10 m; 0,10-0,20 m; 0,20-0,30 m e, também, nos dias 24 a 29 de março de 2007, a densidade do solo (DS) nas mesmas profundidades. $\mathrm{O}$ método empregado para a determinação dos atributos físicos do solo foi aquele preconizado pela Embrapa (1997). Com o uso de um trado de caneca foram retiradas amostras deformadas de solo para determinar a umidade gravimétrica (UG), expressa em $\left[\mathrm{kg} \mathrm{kg}^{-1}\right]$. Adensidade do solo (DS) foi determinada pelo método do anel volumétrico, expressa em $\left[\mathrm{kg} \mathrm{dm}^{-3}\right]$. A resistência do solo à penetração (RP) foi obtida com penetrômetro de impacto, modelo IAA/ Planalsucar/Stolf. Os perfis de resistência do solo à penetração foram avaliados para as três profundidades já citadas e a expressão utilizada para o cálculo, determinada por Stolf (1991), foi a mesma utilizada por Carvalho et al. (2006), fornecendo os valores em [MPa]. A umidade volumétrica foi calculada pela seguinte equação:

$\mathrm{UV}=\mathrm{UG} \cdot \mathrm{DS}$

em que: UV é a umidade volumétrica $\mathrm{m}^{3} \cdot \mathrm{m}^{-3}$, UG é a umidade gravimétrica $\mathrm{kg} \mathrm{kg}^{-1}$ e DS é a densidade do solo $\mathrm{kg} \mathrm{dm}^{-3}$. Dessa forma, a relação dos 12 atributos do solo estudados foi: DS1, DS2, DS3, UG1, UG2, UG3, UV1, UV2, UV3, RP1, RP2 e RP3.

A análise descritiva inicial, a matriz de correlação e a análise de regressão entre os atributos estudados foram efetuadas com o aplicativo SAS (Schlotzhaver \& Littlel, 1997). De acordo com Pimentel Gomes \& Garcia (2002), a variabilidade de um atributo pode ser classificada segundo a magnitude de seu coeficiente de variação (CV). Suas classes foram determinadas como baixa $(\mathrm{CV} \leq 10 \%)$, mé$\operatorname{dia}(10 \%<\mathrm{CV} \leq 20 \%)$, alta $(20 \%<\mathrm{CV} \leq 30 \%)$ e muito alta 
(CV > 30\%). A análise geoestatística foi realizada com o uso do Gamma Design Software 7.0 (GS+, 2004). Os ajustes dos semivariogramas simples e cruzados, em função de seus modelos, foram efetuados preferencialmente pela seleção do menor valor da soma dos quadrados dos desvios. A decisão final dos modelos a serem utilizados foi realizada pela análise da validação cruzada, levando-se em conta o valor do coeficiente de correlação e o valor do b da equação. A análise da dependência espacial (ADE) foi efetuada conforme a mesma expressão, contida em Kitamura et al. (2007).

\section{RESULTADOS E DISCUSSÃO}

Na Tabela 1, está apresentada a análise descritiva dos atributos estudados. Assim, a produtividade de massa de matéria seca da consorciação de forragens (MSF) apresentou alta variabilidade, com coeficiente de variação igual a 29,0\%, variação que pode ser atribuída ao manejo adotado, que, pelo fato de revolver o solo, eleva a variação de seus atributos físicos, consequentemente, também, a da MSF. Esses dados concordam com os de Bordin et al. (2008), que obtiveram variabilidade de $21,4 \%$, para a produção de guandu e milheto isoladamente, sob diferentes sistemas de manejo (escarificado e não escarificado), num Latossolo Vermelho distroférrico, discordando de dados apresentados por Lima (2007), que trabalhou com a massa seca da forragem de milho em um Latossolo Vermelho distroférrico e encontrou variabilidade média com coeficiente de variação de $16,3 \%$ e, também, do valor observado por Cavallini et al. (2010), que foi tido como um coeficiente de variação muito alto, de $32,6 \%$, para a massa de matéria seca da forragem de Braquiaria brizantha Hochst Stapf.

A variabilidade da densidade do solo (DS -Tabela 1) apresentou-se baixa nas três profundidades nas quais os valores de DS1, DS2 e DS3 foram 10,0; 8,6 e 9,1\%, respectivamente. Esses valores assemelham-se aos obtidos por Lima (2007), que trabalhou em um Latossolo Vermelho distroférrico sob plantio direto, numa malha geoestatística constituída de 125 pontos amostrais e encontrou variabilidade baixa para os atributos acima citados, sendo os respectivos valores de 9,8; 3,1 e 4,1\%. Montanari et al. (2008) também encontraram variabilidade baixa para a densidade do solo nas profundidades $0,00-0,10 ; 0,10-0,20$; 0,20-0,30 e 0,30-0,40 m, em um Latossolo Vermelho distroférrico sob plantio direto, em uma rede de 165 x $60 \mathrm{~m}$, com coeficientes de variação entre 4,1 e 5,6\%.

$\mathrm{O}$ atributo resistência mecânica do solo à penetração (RP) apresentou variabilidade muito alta, com valores de RP1, RP2 e RP3 iguais a 60,2; 51,2 e 38,5\%, respectivamente, concordando com resultados de Souza et al. (2004), quando estudaram esse atributo em um Latossolo Verme- lho distrófico sob cultivo de cana-de-açúcar e observaram, também, valores de coeficientes de variação muito altos, sendo de 38,0; 37,7 e 36,0\%, para as profundidades, 0,0-0,15; 0,15-0,30 e 0,30-0,45 m.

Em relação aos valores encontrados para os atributos umidade gravimétrica (UG) e umidade volumétrica (UV), somente a UG, na profundidade 0,20-0,30 m, apresentou variabilidade baixa, com coeficiente de variação 8,8\%. Os demais atributos, nas camadas de $0,0-0,10 ; 0,10-0,20$, para UG, e 0,0-0,10; 0,10-0,20 e 0,20-0,30 m, para a UV, apresentaram variabilidade média com coeficiente de variação de 15 a 12,2\%, para a UG, e 17,5; 14,2 e 12,5\%, para a UV. Esses dados discordam dos de Rosa Filho et al. (2009), que, trabalhando com duas profundidades $(0,0-0,10$ e 0,10 $0,20 \mathrm{~m}$ ), encontraram variabilidade baixa para o atributo umidade volumétrica, na primeira e segunda camadas (UV1 e UV2), com coeficiente de variação de 6,1 e 4,5\%, respectivamente. Contudo, os dados deste trabalho concordam com os de Lima et al. (2007), que encontraram média variabilidade para UG2 e baixa para UG3, com valores de coeficiente de variação de 13,1 e 8,8\%, respectivamente, mas não concordando quanto ao de UG1, que apresentou alta variabilidade, com coeficiente de variação igual a $21,7 \%$.

Quando uma variável estatística qualquer tem distribuição de frequência do tipo normal, a medida de tendência central mais adequada para representá-la deve ser a média. Será a mediana, ou a média geométrica, caso possua distribuição de frequência do tipo lognormal (Spiegel, 1985). Para os atributos apresentados na (Tabela 1), a distribuição de frequência foi do tipo normal para a MSF, UG2, UG3, UV1 e UV3, com coeficientes de assimetria positiva entre 0,025 e 0,396 . Os coeficientes de curtose positiva ficaram entre 0,021 e 0,856 , e os da negativa foram de $-0,743$ e -0,390. Com relação aos atributos RP1, RP3, UG1 e UV2, a distribuição de frequência foi do tipo lognormal, com coeficientes de assimetria positiva entre 0,134 e 0,336, assim como o da negativa que foi de $-0,125$. Já os coeficientes de curtose positiva foram de 0,148 a 0,654 , e os da negativa foram de $-0,777$ a $-0,591$. Para DS2, a distribuição foi tendendo a normal, com coeficiente de assimetria positiva de 0,147 e curtose negativa de -0,993. Para os atributos DS1, DS2 e RP2, apenas o segundo apresentou-se do tipo indeterminado, uma vez que nos demais a distribuição tendeu a lognormal.

Dessa forma, conforme o atributo considerado a distribuição de frequência do tipo normal concorda com o observado pelos autores listados abaixo. MSF: Lima et al. (2007), trabalhando em Latossolo Vermelho distrófico, com produção de matéria seca de forragem em milho. UG: Freddi et al. (2006), trabalhando em Latossolo Vermelho sob preparo convencional. UV: Marins (2006), trabalhando em Latossolo cultivado com soja. A distribuição de frequência do atributo RP apresentou-se do tipo lognormal nas pro- 
Tabela 1. Análise descritiva inicial de alguns atributos da produtividade da massa de matéria seca da consorciação de forragens e de um Latossolo Vermelho distroférrico de Selvíria (MS)

\begin{tabular}{|c|c|c|c|c|c|c|c|c|c|c|}
\hline \multicolumn{11}{|c|}{ Medidas estatísticas descritivas } \\
\hline \multirow[t]{2}{*}{ Atributo $^{\text {(a) }}$} & \multirow[t]{2}{*}{ Média } & \multirow[t]{2}{*}{ Mediana } & \multicolumn{2}{|c|}{ Valor } & \multirow{2}{*}{$\begin{array}{l}\text { Desvio } \\
\text { Padrão }\end{array}$} & \multicolumn{3}{|c|}{ Coeficiente } & \multicolumn{2}{|c|}{ Probabilidadedo teste $\mathrm{e}^{(\mathrm{b})}$} \\
\hline & & & Mínimo & Máximo & & Variação (\%) & Curtose & Assimetria & $\operatorname{Pr}<w$ & DF \\
\hline \multicolumn{11}{|c|}{ Atributo da planta } \\
\hline MSF (kg.ha-1) & 19209 & 18336 & 4924 & 33520 & 5576 & 29,0 & 0,021 & 0,396 & 0,113 & NO \\
\hline \multicolumn{11}{|c|}{ Densidade do solo } \\
\hline $\mathrm{DS} 1\left(\mathrm{~kg} \cdot \mathrm{dm}^{-3}\right)$ & 1,292 & 1,259 & 1,059 & 1,653 & 0,132 & 10,1 & $-0,614$ & 0,331 & 0,032 & $\mathrm{TL}$ \\
\hline DS2 $\left(\mathrm{kg} \cdot \mathrm{dm}^{-3}\right)$ & 1,304 & 1,291 & 1,097 & 1,550 & 0,112 & 8,6 & $-0,993$ & 0,147 & 0,013 & $\mathrm{TN}$ \\
\hline $\operatorname{DS} 3\left(\mathrm{~kg} \cdot \mathrm{dm}^{-3}\right)$ & 1,334 & 1,346 & 1,077 & 1,553 & 0,121 & 9,1 & $-0,987$ & $-0,304$ & - & IN \\
\hline \multicolumn{11}{|c|}{ Resistência à penetração } \\
\hline RP1 (MPa) & 2,950 & 2,334 & 0,904 & 8,226 & 1,782 & 60,2 & $-0,591$ & 0,336 & 0,034 & $\mathrm{LN}$ \\
\hline RP2 (MPa) & 3,118 & 2,735 & 1,036 & 7,675 & 1,597 & 51,2 & $-0,964$ & 0,104 & 0,019 & $\mathrm{TL}$ \\
\hline RP3 (MPa) & 2,983 & 2,694 & 1,036 & 6,017 & 1,149 & 38,5 & $-0,777$ & $-0,125$ & 0,073 & $\mathrm{LN}$ \\
\hline \multicolumn{11}{|c|}{ Umidade gravimétrica } \\
\hline UG1 $\left(\mathrm{kg} \mathrm{kg}^{-1}\right)$ & 0,181 & 0,177 & 0,108 & 0,259 & 0,027 & 15,0 & 0,654 & 0,158 & 0,049 & $\mathrm{LN}$ \\
\hline $\mathrm{UG} 2\left(\mathrm{~kg} \mathrm{~kg}^{-1}\right)$ & 0,206 & 0,204 & 0,145 & 0,270 & 0,023 & 11,2 & 0,040 & 0,134 & 0,925 & NO \\
\hline UG3 $\left(\mathrm{kg} \mathrm{kg}^{-1}\right)$ & 0,224 & 0,223 & 0,178 & 0,299 & 0,020 & 8,8 & 0,856 & 0,283 & 0,109 & NO \\
\hline \multicolumn{11}{|c|}{ Umidade volumétrica } \\
\hline $\mathrm{UV} 1\left(\mathrm{~m}^{3} \cdot \mathrm{m}^{-3}\right)$ & 0,231 & 0,223 & 0,139 & 0,335 & 0,040 & 17,5 & $-0,390$ & 0,356 & 0,083 & NO \\
\hline $\mathrm{UV} 2\left(\mathrm{~m}^{3} \cdot \mathrm{m}^{-3}\right)$ & 0,268 & 0,264 & 0,190 & 0,381 & 0,038 & 14,2 & 0,148 & 0,134 & 0,694 & $\mathrm{LN}$ \\
\hline $\operatorname{UV} 3\left(\mathrm{~m}^{3} \cdot \mathrm{m}^{-3}\right)$ & 0,300 & 0,297 & 0,220 & 0,387 & 0,037 & 12,5 & $-0,743$ & 0,025 & 0,210 & NO \\
\hline
\end{tabular}

(a) MSF = produtividade da massa de matéria seca da consorciação de forragens; DS, RP, UG e UV, de 1 a 3, são respectivamente a densidade do solo, resistência à penetração, umidade gravimétrica e umidade volumétrica do solo; (b) $\mathrm{DF}=$ distribuição de frequência, sendo NO, LN, TN, TL e IN respectivamente do tipo normal, lognormal, tendendo a normal, tendendo a lognormal e indefinida. 
fundidades de 0,0-0,10 e 0,20-0,30 m, concordando com resultados de Santos et al. (2005), que trabalharam em um mesmo solo, analisando a produtividade de grãos de feijão e obtiveram distribuição lognormal para todas as profundidades. Já a distribuição de frequência tendendo a normal do atributo DS2 discorda dos resultados de Lima (2007), que trabalhando em Latossolo Vermelho distrófico, encontrou distribuição normal para densidade, na camada de $0,10-0,20 \mathrm{~m}$.

$\mathrm{O}$ valor da média para massa de matéria seca da forragem foi de $19209 \mathrm{~kg} \mathrm{ha}^{-1}$, na consorciação, 2,4\% abaixo da média de produtividade do milheto, isoladamente, e acima da produção de guandu (Tabela 1). Maior Junior (2006), estudando arranjos populacionais de feijão guandu em região semiárida, sob Luvissolo Crômico órtico, obteve produtividade de massa de matéria seca média de $1790 \mathrm{~kg}$ ha $^{-1}$ e Pires et al. (2007), trabalhando com cultivares de milheto em Latossolo Vermelho distrófico, encontraram produtividade média de até $19690 \mathrm{~kg} \mathrm{ha}^{-1}$ de massa de matéria seca da forragem.

Os valores médios para densidade do solo (Tabela 1) DS1, DS2 e DS3, foram de $1,259 \mathrm{~kg} \mathrm{dm}^{-3}, 1,304 \mathrm{~kg} \mathrm{dm}^{-3} \mathrm{e}$ $1,334 \mathrm{~kg} \mathrm{dm}^{-3}$, respectivamente, apresentando uma tendência direta com o aumento da profundidade no perfil do solo, corroborando o aumento da compactação nas camadas mais profundas, concordando com os dados de Montanari et al. (2010, 2011). Dessa forma, provavelmente, a camada superficial do solo apresentou-se menos compactada, pela maior concentração de raízes que o sistema radicular da consorciação (feijão guandu+milheto) pôde adicionar, aliado ao sistema utilizado para o preparo do solo (cultivo mínimo), que, por outro lado, provocou maior compactação nas camadas inferiores $(0,20-0,30 \mathrm{~m})$, por causa do efeito "pé-de-arado" ou "pé-de-grade" (Vieira et al., 1989). Assim, esses dados ficaram de acordo com aqueles dos trabalhos de Souza et al. (2004), Lima et al. (2008) e Freddi et al. (2006), os quais apresentaram essa mesma tendência. Por outro lado, ficaram consideravelmente abaixo do valor crítico $\left(1,850 \mathrm{~kg} \mathrm{dm}^{-3}\right)$ indicado por Bowen (1981), o qual é capaz de afetar o desenvolvimento radicular e, consequentemente, a produtividade vegetal.

Para a umidade gravimétrica, os valores de UG1, UG2 e UG3 foram 0,177; 0,206 e 0,224 $\mathrm{kg} \mathrm{kg}^{-1}$, respectivamente. Bengough et al. (2001) relataram que a condição ideal de umidade do solo, para a coleta dos dados de resistência à penetração, é aquela que se observa quando ele se apresenta com umidade variando entre a capacidade de campo e $2 / 3$ terços dessa capacidade, isto é, quando apresentar uma umidade volumétrica, na microporosidade, variando entre 0,330 e $0,220 \mathrm{~m}^{3} \mathrm{~m}^{-3}$ (Kiehl, 1979). Portanto, uma vez que a capacidade de campo do solo em questão, determinada por Martins (2007), foi de $0,351 \mathrm{~m}^{3} \mathrm{~m}^{-3}$, deve- se salientar que os dados desta pesquisa foram coletados em ótimas condições de umidade volumétrica do solo $\left(0,231 ; 0,264 \mathrm{e} 0,300 \mathrm{~m}^{3} \mathrm{~m}^{-3}\right.$, para as profundidades 0,0 0,$10 ; 0,10-0,20$ e $0,20-0,30 \mathrm{~m}$, respectivamente - Tabela 1 ), uma vez que os valores de resistência mecânica à penetração foram de 2,334; 2,735 e 2,694 MPa, para as profundidades $0,0-0,10 ; 0,10-0,20$ e $0,20-0,30 \mathrm{~m}$, respectivamente. Esses valores, segundo a classificação de Arshad et al. (1996), são altos. Assim, eles também puderam corroborar o aumento da compactação nas camadas inferiores do solo, a exemplo do que havia sido observado para a densidade do solo, que sofreu incremento de valor, da camada superficial para a subsuperficial. No entanto, como já discutido, o valor da produtividade de massa de matéria seca da forragem foi satisfatório para a região estudada, já que as duas espécies têm sistema radicular agressivo e toleram estresse hídrico.

$\mathrm{Na}$ Tabela 2, está apresentada a matriz de correlação linear simples entre a produtividade da massa de matéria seca da consorciação de forragens (MSF) e os atributos físicos do solo (DS, UG, UV e RP).

A correlação entre a produtividade da massa de matéria seca da forragem (MSF) e os atributos físicos do solo (Tabela 2) não apresentou significância para nenhum par.

No geral, as correlações entre os pares de atributos do solo (Tabela 2) apresentaram-se, quando analisados, dois atributos quaisquer dentro da mesma profundidade, com o sinal positivo (correlação direta) ou negativo (correlação indireta) para todas aquelas estabelecidas nas três profundidades. Os atributos de correlação direta, com os respectivos valores de coeficiente de correlação, foram: DS x UV $\left(0,710^{* *}\right.$ a $\left.0,226^{*}\right)$ e UG x UV $\left(0,749^{* *}\right.$ a $\left.0,291^{* *}\right)$. Já os de correlação indireta foram: UV x RP $\left(-0,295^{* *}\right.$ a $\left.-0,182^{*}\right)$ e UG x RP (-0,444* a -0,191*). O par RP x UG apresentou correlação indireta e significativa entre seus atributos, corroborando a teoria pedológica sobre esse fato (Montanari et al., 2010). Assim, com o aumento da UG ocorrerá uma diminuição da RP e vice-versa. Este resultado concordou com o de Santos et al. (2005), os quais, trabalhando em Latossolo Vermelho distrófico de Selvíria (MS), sob plantio convencional, também obtiveram correlação inversa, com coeficientes de correlação entre eles de $-0,351^{* *}$ a $-0,208^{*}$. Entretanto, discordou daquele de Carvalho et al. (2006), os quais, também, trabalhando em Latossolo Vermelho distroférrico de Selvíria (MS), obtiveram correlação direta entre eles $\left(r=0,161^{*}\right.$ a $\left.0,171^{*}\right)$. Rosa Filho et al. (2009) correlacionando densidade do solo (DS) e umidade volumétrica (UV) em Latossolo Vermelho distroférrico também verificaram correlação direta e significativa para o primeiro e o segundo nível, com valores de coeficiente de correlação de $0,695^{* *}$ e $0,761^{* *}$, respectivamente. 


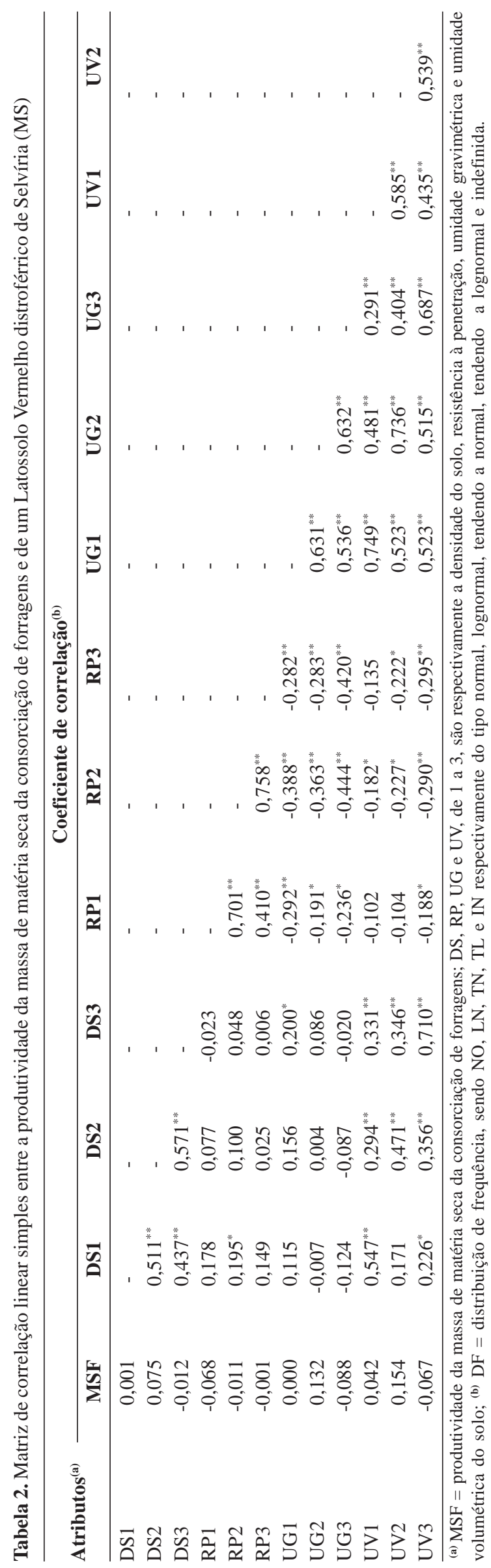

Na Tabela 3, estão apresentados os parâmetros dos semivariogramas simples, ajustados para produtividade da massa de matéria seca da consorciação de forragens, e alguns atributos físicos de um Latossolo Vermelho distroférrico de Selvíria (MS).

No tocante ao desempenho dos semivariogramas (Tabela 3), sua relação decrescente, analisada pela grandeza do coeficiente de determinação espacial $\left(\mathrm{r}^{2}\right)$, foi a seguinte: 1-DS1 (0,950), 2-UV1 (0,939), 3-DS2 (0,917), 4-DS3 (0,897), 5- UG1 (0,733), 6-MSF (0,706) e 7- RP3 (0,622). Assim, em relação aos três primeiros, que tiveram elevados coeficientes de determinação espacial, observou-se o seguinte: para o primeiro (DS1), o valor do $\mathrm{r}^{2}(0,950)$ indicou ser este o atributo de melhor ajuste semivariográfico, e de acordo com aqueles observados por Santos et al. (2006) e Lima et al. (2007), os quais variaram entre 0,819 e 0,906 . Em relação ao ADE, os altos valores observados para DS2 $(99,4 \%) \mathrm{e}$ DS1 $(88,6 \%)$ concordam com os resultados de Lima (2007) somente quanto a DS1, para o qual o autor encontrou valor alto, de $92,6 \%$, discordando quanto ao de DS2, para o qual o mesmo autor obteve valor moderado de $61,4 \%$. Já para a profundidade de $0,20-0,30 \mathrm{~m}$, o dado da avaliação de dependência espacial (ADE) foi moderado $(60,5 \%)$, concordando com resultados de Lima et al. (2007) que encontraram valor moderado de $26,0 \%$.

O modelo ajustado para densidade do solo foi exponencial para DS1 e DS2, discordando de resultados de Schaffrath et al. (2008), que, trabalhando com Latossolo Vermelho distroférrico, sob plantio direto e preparo convencional, encontraram modelo esférico para os dois sistemas, na profundidade de $0,0-0,15 \mathrm{~m}$, com um total de 128 pontos amostrados. Santos et al. (2006) encontraram modelo esférico para o segundo nível, segundo os dados obtidos. Com relação a UV1, que apresentando valor de $\mathrm{r}^{2}$ igual a 0,939 , mostrou ser o atributo de segundo melhor ajuste semivariográfico, com ADE forte, sendo o valor encontrado de $86,5 \%$.

$\mathrm{Na}$ Tabela 3, a relação decrescente dos alcances foi a seguinte: 1-DS1 (16,4 m); 2-RP3 (11,3 m); 3-MSF (8,3 m); 4DS3 (7,8 m), 5-UV1 (7,8 m); 6-DS2 (7,4 m) e 7-UG1 (4,0 m). Com relação ao atributo RP, Roque et al. (2008), trabalhando sob sistema semeadura direta nas safras de 2005 e 2006, obtiveram alcances superiores, com valores de $23,3 \mathrm{~m}$ e $16,96 \mathrm{~m}$, respectivamente. Portanto, nas condições desta pesquisa, assim como, visando a auxiliar pesquisa futura, na qual os mesmos atributos estejam envolvidos, os valores dos alcances a serem utilizados nos pacotes geoestatísticos, que alimentarão os pacotes computacionais empregados na agricultura de precisão, no geral, não deverão ser menores do que $4,0 \mathrm{~m}$. Por outro lado, exclusivamente para o atributo produtividade de massa de matéria seca da consorciação de forragens, os alcances não deverão ser menores do que $8,3 \mathrm{~m}$, sob sistema cultivo mínimo. 
Na Figura 1, estão apresentados o semivariograma cruzado, a validação cruzada e o mapa de co-krigagem da massa de matéria seca da consorciação de forragens, em função da densidade do solo, de um Latossolo Vermelho distroférrico de Selvíria (MS). No geral, esse foi o único semivariograma cruzado obtido no âmbito de correlação entre planta versus solo, sendo estabelecido para o atributo $\mathrm{MSF}=\mathrm{f}(\mathrm{DS} 3)$, cujo coeficiente de determinação espacial foi de 0,172 , dependência espacial alta $(92,6 \%)$, alcance de 11,2 m, sendo o modelo ajustado o esférico. Essa correlação inversa mostra um incremento da produtividade em locais de maior densidade do solo, provavelmente devido ao aumento da microporosidade, consequientemente do teor de água no solo, além do acrescentamento do contato solo/raiz, ocorrendo assim, maior absorção de nutrientes pela consorciação guandu com milheto. Schaffrath et al. (2008), trabalhando no sistema plantio direto, também encontraram correlação inversa, porém entre densidade do solo e macroporosidade, em que obtiveram alcance de $9,2 \mathrm{~m}$, sendo o modelo ajustado o exponencial.

Na Figura 2, estão apresentados os semivariogramas simples e os mapas de krigagem da massa de matéria seca da consorciação de forragens (MSF) e da densidade do solo na profundidade 0,20-0,30 m (DS3), em Latossolo Vermelho distroférrico de Selvíria (MS). Para a MSF, o coeficiente de determinação espacial foi de 0,706 , dependência espacial moderada (50,0\%), alcance de $8,3 \mathrm{~m}$, sendo o modelo ajustado o gaussiano, discordando dos valores encontrados por Cavallini et al. (2010), que. traba-

Tabela 3. Parâmetros dos semivariogramas simples ajustados da produtividade da massa seca da consorciação de forragens e de alguns atributos físicos de um Latossolo Vermelho distroférrico de Selvíria (MS)

\section{Parâmetros}

\begin{tabular}{|c|c|c|c|c|c|c|c|c|}
\hline \multirow[t]{2}{*}{ Atributo $^{(a)}$} & \multirow[t]{2}{*}{ Modelo (b) } & \multirow{2}{*}{$\begin{array}{l}\text { Efeito Pepita } \\
\qquad\left(\mathrm{C}_{0)}\right.\end{array}$} & \multirow{2}{*}{$\begin{array}{c}\text { Patamar } \\
\left(\mathrm{C}_{0}+\mathrm{C}\right)\end{array}$} & \multirow{2}{*}{$\begin{array}{l}\text { Alcance } \\
\left(A_{0}\right)(m)\end{array}$} & \multirow[t]{2}{*}{$\mathbf{r}^{2}$} & \multirow[t]{2}{*}{$\mathbf{S Q R}^{(\mathrm{c})}$} & \multicolumn{2}{|c|}{$\begin{array}{c}\text { Avaliador da } \\
\text { dependência espacia }\end{array}$} \\
\hline & & & & & & & $\mathbf{A D E} \mathbf{E}^{(\mathrm{d})}$ & Classe \\
\hline \multicolumn{9}{|c|}{$\tilde{a}(\mathrm{~h})$ simples dos atributos da planta } \\
\hline $\operatorname{MSF}\left(\mathrm{kg} \mathrm{ha}^{-1}\right)$ & gau & $1,023.10^{10}$ & $2,047.10^{10}$ & 8,3 & 0,706 & $3,85.10^{13}$ & 50,0 & Moderada \\
\hline \multicolumn{9}{|c|}{$\tilde{a}(h)$ simples dos atributos do solo } \\
\hline DS1 $\left(\mathrm{kg} \mathrm{dm}^{-3}\right)$ & $\exp$ & $1,980.10^{-3}$ & $1,706.10^{-2}$ & 16,4 & 0,950 & $8,54 \cdot 10^{-6}$ & 88,4 & Forte \\
\hline $\mathrm{DS} 2\left(\mathrm{~kg} \mathrm{dm}^{-3}\right)$ & $\exp$ & $6,000 \cdot 10^{-5}$ & $1,042 \cdot 10^{-2}$ & 7,4 & 0,917 & $2,61.10^{-6}$ & 99,4 & Forte \\
\hline $\mathrm{DS} 3\left(\mathrm{~kg} \mathrm{dm}^{-3}\right)$ & esf & $5,640.10^{-3}$ & $1,428 \cdot 10^{-2}$ & 7,8 & 0,897 & $4,47.10^{-6}$ & 60,5 & Moderada \\
\hline RP1 (MPa) & epp & 3,344 & 3,344 & - & - & - & - & - \\
\hline \#RP2 (MPa) & epp & 1,701 & 1,701 & - & - & - & - & - \\
\hline RP3 (MPa) & $\exp$ & $5,500 \cdot 10^{-1}$ & 1,174 & 11,3 & 0,622 & $1,12.10^{-1}$ & 53,2 & Moderada \\
\hline UG1 ( $\left.\mathrm{kg} \mathrm{kg}^{-1}\right)$ & gau & $2,303 \cdot 10^{-4}$ & $4,860 \cdot 10^{-4}$ & 4,0 & 0,733 & $1,17.10^{-8}$ & 52,6 & Moderada \\
\hline \#UG2 $\left(\mathrm{kg} \mathrm{kg}^{-1}\right)$ & epp & $3,900 \cdot 10^{-4}$ & $3,900 \cdot 10^{-4}$ & - & - & - & - & - \\
\hline \#UG3 $\left(\mathrm{kg} \mathrm{kg}^{-1}\right)$ & epp & $2,580 \cdot 10^{-4}$ & $2,580 \cdot 10^{-4}$ & - & - & - & - & - \\
\hline $\mathrm{UV} 1\left(\mathrm{~m}^{3} \mathrm{~m}^{-3}\right)$ & $\exp$ & $2,020 \cdot 10^{-4}$ & $1,494 \cdot 10^{-3}$ & 7,8 & 0,939 & $2,48.10^{-8}$ & 86,5 & Forte \\
\hline $\operatorname{UV} 2\left(\mathrm{~m}^{3} \mathrm{~m}^{-3}\right)$ & epp & $1,416.10^{-3}$ & $1,416 \cdot 10^{-3}$ & - & - & - & - & - \\
\hline $\operatorname{UV} 3\left(\mathrm{~m}^{3} \mathrm{~m}^{-3}\right)$ & epp & $1,386 \cdot 10^{-3}$ & $1,386 \cdot 10^{-3}$ & - & - & - & - & - \\
\hline
\end{tabular}

(a) MSF = produtividade da massa de matéria seca da consorciação de forragens; DS, RP, UG e UV, de 1 a 3, são respectivamente a densidade do solo, resistência à penetração, umidade gravimétrica e umidade volumétrica do solo; ${ }^{(b)}$ esf $=$ esférico , exp = exponencial, gau = gaussiano e epp = efeito pepita puro; (c) $\mathrm{SQR}=$ soma dos quadrados dos resíduos; ( ${ }^{\mathrm{d})} \mathrm{ADE}=$ avaliador da dependência espacial, \# = significa que foi extraído tendência pelo método do refinamento da mediana.

MSF=f(DS3)

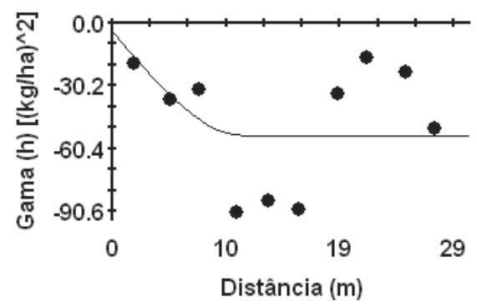

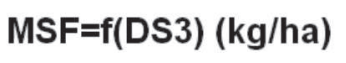

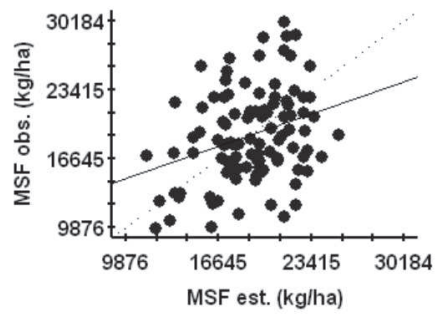

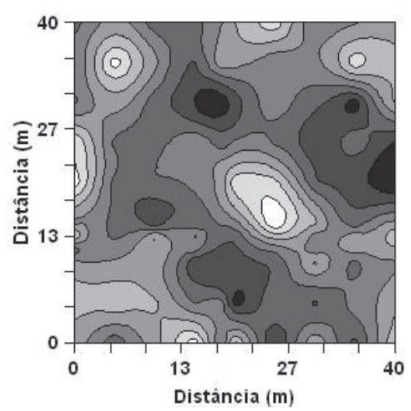

MSF $=$ (DS3) (kgha)

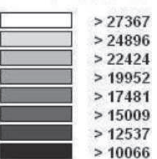

Figura 1. Semivariograma cruzado, validação cruzada e mapa de co-krigagem da produtividade da massa de matéria seca da consorciação de forragens (MSF) em função da densidade do solo (DS3) de um Latossolo Vermelho distroférrico de Selvíria (MS). 

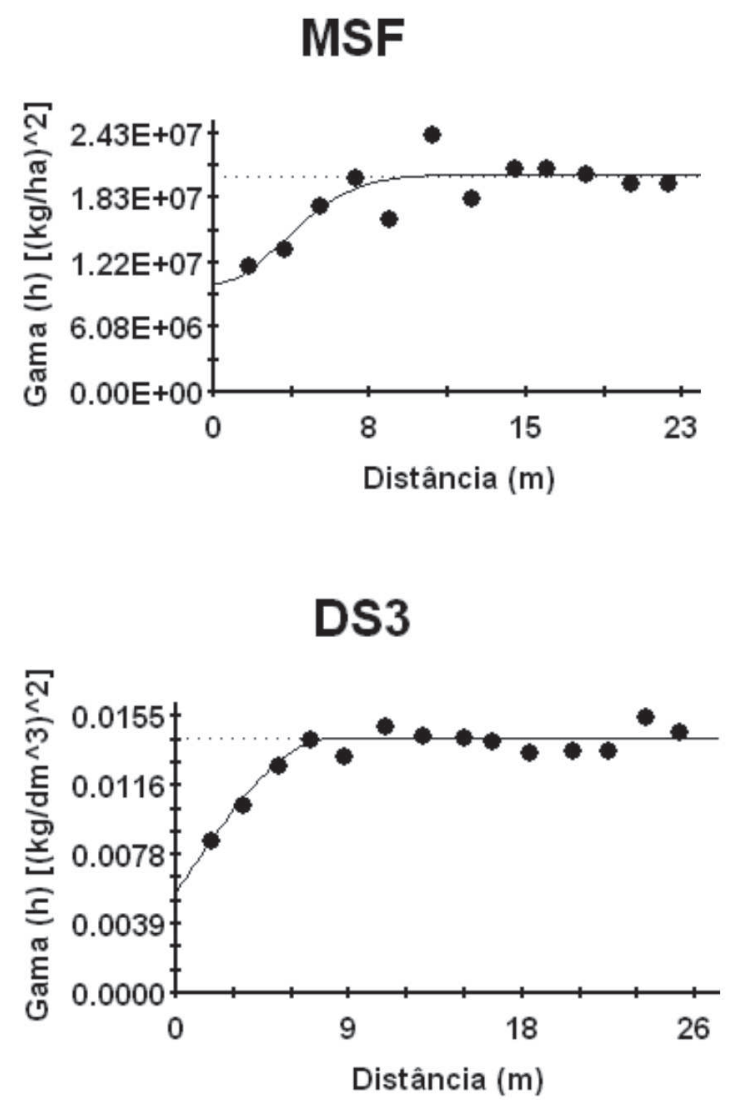
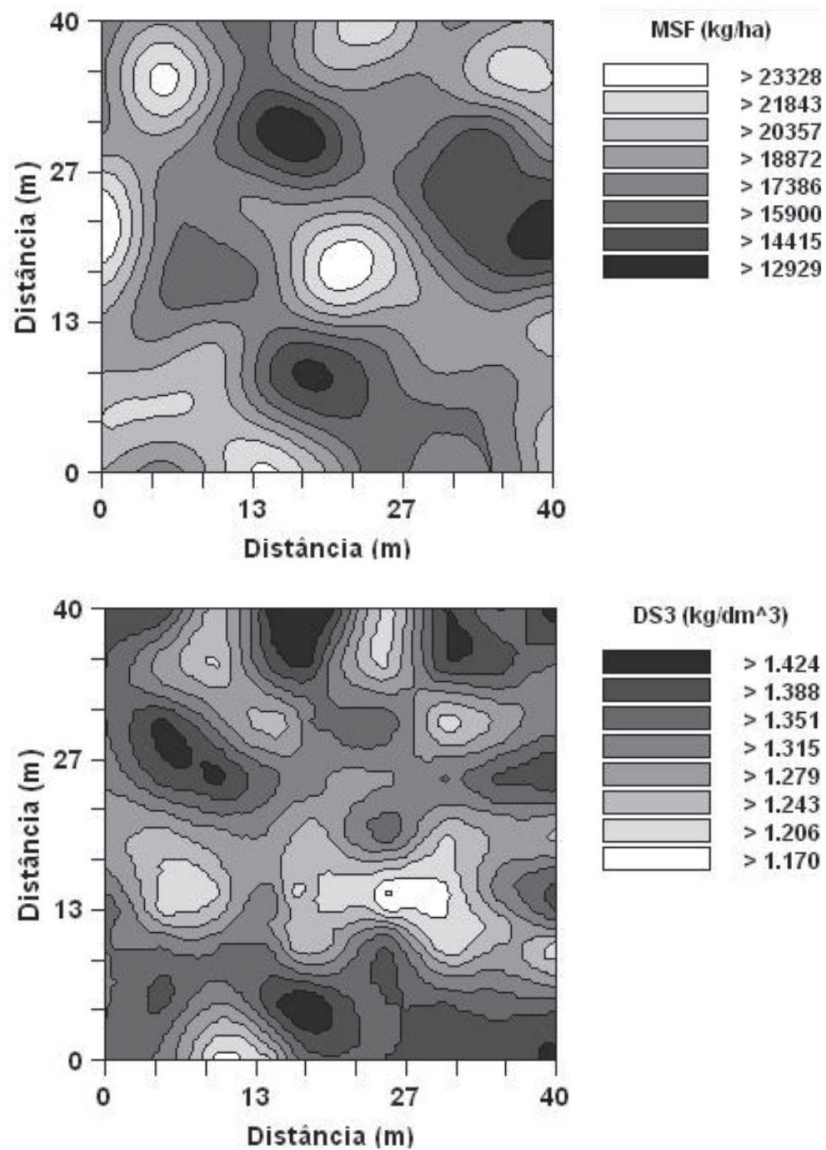

$\operatorname{DS} 3\left(\mathbf{k g} / \mathrm{dm}^{\wedge} 3\right)$

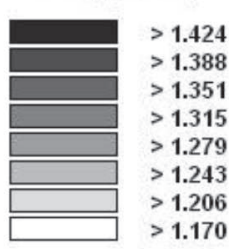

Figura 2. Semivariogramas simples e mapas de krigagem da massa de matéria seca da consorciação de forragens (MSF) e da densidade do solo na profundidade de 0,20-0,30 m (DS3) em um Latossolo Vermelho distroférrico de Selvíria (MS).

lhando com relações entre produtividade de Brachiaria brizantha e atributos físicos de um Latossolo do cerrado, encontraram, para ajuste do semivariograma, do mesmo atributo em estudo neste trabalho, o modelo esférico, coeficiente de determinação espacial de 0,865 , alcance de 49,4 m. Em relação ao DS3, o coeficiente de determinação espacial foi de 0,897 , o alcance de 7,8 m, sendo o modelo ajustado o esférico, também discordando dos valores encontrados por Cavallini et al. (2010) com o coeficiente de determinação espacial de 0,830, e alcance de 73,5 m.

\section{CONCLUSÕES}

A produtividade da massa de matéria seca da consorciação da forragem foi elevada e acima da produção esperada de guandu e milheto, em manejo escarificado.

Não houve correlação linear entre os atributos físicos do solo estudados com a produtividade da massa de matéria seca da consorciação (guandu + milheto) sob sistema cultivo mínimo.

A umidade volumétrica e a umidade gravimétrica foram os atributos que mais se relacionaram para estimar a qualidade física do solo, junto com a densidade do solo e a resistência mecânica à penetração.
No âmbito da correlação espacial, o atributo que melhor explicou a produtividade da massa de matéria seca da consorciação foi a densidade do solo na camada de 0,20 $0,30 \mathrm{~m}$, com uma correlação inversa, indicando que as espécies desenvolvem-se bem em solos adensados.

\section{REFERÊNCIAS}

Andreotti M, Araldi M, Guimarães VF, Furlani E \& Buzetti S (2008) Winter corn yield and chemical modifications in latosol as a function of covering species after lime application under notillage system. Acta Scientiarum, 30:109-115.

Arshad MA, Lower B \& Grossman B (1996) Physical tests for monitoring soil quality. In: Doran JW \& Jones AJ (Eds.). Methods for assessing soil quality. Madison, Soil Science Society of America Journal. p.123-141, (Special Publication, 49).

Basso FC, Andreotti M, Carvalho MP, Lodo B, Montanari, R (2011). Correlação linear e espacial entre a produtividade e o teor de proteína bruta do guandu anão e os atributos de um Latossolo. Revista Brasileira de Ciências Agrárias, 6:369-377.

Bengough AG, Campbell DJ, O' Sullivan MF (2001) Penetrometer Techniques in relation to Soil Compaction and Root Growth. In: Soil and environmental analysis: physical methods. 2. ed., New York, Marcel Decker. p.377-403.

Bordin I, Neves CSVJ, Francio Filho P, Preti EA \& Cardoso C (2008) Crescimento de milheto e guandu, desempenho de plantas cítricas e propriedades físicas do solo escarificado em um pomar. Revista Brasileira de Ciência do Solo, 32:1409-1418. 
Bowen HD (1981) Alleviating mechanical impedance. In: Arkin GF, Taylor HM, (Comp.) Modifiying the root environment to reduce crop estress. St. Josefh, American Society of Agricutural Engineers. p.21-57.

Carvalho G.J, Carvalho MP, Freddi OS \& Martins MV (2006) Correlação da produtividade do feijão com a resistência do solo à penetração sob plantio direto. Revista Brasileira Engenharia Agrícola Ambiental, 10:765-771.

Cavallini MC, Andreotti M, Oliveira LL, Pariz CM \& Carvalho MP (2010) Relações entre produtividade de Brachiaria Brizantha e atributos físicos de um latossolo do cerrado. Revista Brasileira de Ciência do Solo, 34:1007-1015.

Dallmeyer AU (1994) Avaliação energética e desempenho operacional de equipamentos de preparo do solo. Tese de Doutorado. Faculdade de Ciências Agronômicas, Universidade Estadual Paulista, Botucatu, 168p.

Embrapa - Empresa Brasileira de Pesquisa Agropecuária (1997) Manual de métodos de análise de solos. $2^{\mathrm{a}}$ ed. Rio de Janeiro, Embrapa, 212p.

Embrapa - Empresa Brasileira de Pesquisa Agropecuária (2006) Sistema brasileiro de classificação de solos. $2^{\mathrm{a}}$ ed. Rio de Janeiro, Embrapa, 306p.

Freddi OS, Carvalho MP, Carvalho GJ \& Veronese Junior V (2006) Produtividade do milho relacionada com a resistência do solo à penetração sob preparo convencional. Engenharia Agrícola, 26:113-121.

$\mathrm{GS}^{+}$: Geostatistics for environmental sciences (2004) $7^{\text {a }}$ ed Plainwell, gamma desing software, Michigan: S.n, 159p.

Kiehl EJ (1979) Manual de edafologia: relações solo-planta. São Paulo, Agronômica Ceres. 264p.

Kitamura AE, Carvalho MP \& Lima CGR (2007) Relação entre a variabilidade espacial das frações granulométricas do solo e a produtividade do feijoeiro sob plantio direto. Revista Brasileira de Ciência do Solo, 31:361-379.

Lima CGR, Carvalho MP, Mello LMM \& Lima RC (2007) Correlação linear e espacial entre a produtividade de forragem, a porosidade total e a densidade do solo em Pereira Barreto (SP). Revista Brasileira de Ciência do Solo, 31:1233-1244.

Lima RC (2007) Produtividade da forragem do milho em função de atributos físicos do solo sob plantio direto na Fazenda Bonança de Pereira Barreto (SP). Dissertação de Mestrado. Faculdade de Engenharia, Universidade Estadual Paulista, Ilha Solteira, $73 \mathrm{p}$.

Lima CLR, Pillon CN, Suzuki LEAS \& Cruz LEC (2008) Atributos físicos de um Planossolo Háplico sob sistemas de manejo comparado aos do campo nativo. Revista Brasileira de Ciência do Solo, 32:1849-1855

Lupatini GC (1996) Produção animal em milheto (Pennisetum americanum (L.) Leeke). Submetido a níveis de adubação nitrogenada. Dissertação de Mestrado. Universidade Federal de Santa Maria, Santa Maria, 129p.

Maior Junior SGS (2006) Efeitos de arranjos populacionais na produção de forragem de feijão guandu (Cajanus cajan (L) Millsp.) em região semi-árida. Dissertação de Mestrado. Centro de Saúde e Tecnologia Rural, Universidade Federal de Campina Grande, Patos, 36p.

Marins AC (2006) Métodos de estimação da função semivariância aplicados a dados simulados e reais de produtividade da soja e de atributos físicos de um Latossolo. Dissertação de Mestrado. Centro de Ciências Exatas e Tecnológicas, Universidade Estadual do Oeste do Paraná, Cascavel, 140p.
Martins MV (2007) Aspectos lineares e espaciais da correlação entre a produtividade de feijão com atributos fisicos do solo. Trabalho de Conclusão de Curso. Faculdade de Engenharia, Universidade Estadual Paulista, Ilha Solteira, 28 p.

Mercante E, Uribe-Opazo MA \& Souza EG (2003) Variabilidade espacial e temporal da resistência mecânica do solo à penetração em áreas com e sem manejo químico localizado. Revista Brasileira de Ciência do Solo, 27:1149-1159.

Montanari R, Pereira GT, Marques Júnior J, Souza ZM, Pazeto RJ \& Camargo LA (2008) Variabilidade espacial de atributos químicos em Latossolo e Argissolos. Ciência Rural, 38:1266-1272.

Montanari R, Carvalho MP, Andreotti M, Dalchiavon FC, Lovera LH \& Honorato MAO (2010) Aspectos da produtividade do feijão correlacionados com atributo físicos do solo sob elevado nível tecnológico de manejo. Revista Brasileira de Ciência do Solo, 34:1811-1822.

Montanari R, Lima RC, Bonini AS, Marques LS, Minguini R, Carvalho MP, Ferreiro J \& Costa NR (2011) Variabilidade dos atributos de um latossolo vermelho sob plantio direto no cerrado brasileiro e produtividade da soja. Cadernos Laboratorio Xeolóxico de Laxe, 36:61-78.

Morton JF, Smith RE, Luco-Lopez MA \& Abrans R (1982) Pigeonpeas (Cajanus cajan Millsp): a valuable crop of the tropics. Mayaguez, Universidad de Puerto Rico - Departament of Agronomy and Soils, 122p.

Pariz CM, Carvalho MP, Chioderoli CA, Nakayama FT, Andreotti M \& Montanari R (2011) Spatial variability of forage yield and soil physical attributes of a Brachiaria decumbens pasture in the Brazilian Cerrado. Revista Brasileira de Zootecnia, 40:2111:2120.

Pimentel-Gomes FP \& Garcia CH (2002) Estatística aplicada a experimentos agronômicos e florestais. Piracicaba, FEALQ, 309 p.

Pires FR, Assis RL, Silva GP, Braz AJBP, Santos SC, Vieira Neto AS \& Sousa JPG (2007) Desempenho Agronômico de Variedades de Milheto em Razão da Fenologia em Pré-Safra. Bioscience Journal, 23:41-49.

Roque MW, Matsura EE, Souza ZM, Bizari DR \& Souza AL (2008) Correlação linear e espacial entre a resistência do solo ao penetrômetro e a produtividade do feijoeiro irrigado. Revista Brasileira de Ciência do Solo, 32:1827-1835.

Rosa Filho G, Carvalho MP, Andreotti M, Montanari R, Binotti FFS \& Gioia MT (2009) Variabilidade da produtividade da soja em função de atributos físicos de um latossolo vermelho distroférrico sob plantio direto. Revista Brasileira de Ciência do Solo, 33:283-293.

Santos PA, Carvalho MP, Freddi OS, Kitamura AE, Freitas EE \& Vanzela LS (2005) Correlação linear e espacial entre o rendimento de grãos do feijoeiro e a resistência mecânica à penetração em um Latossolo Vermelho distroférrico. Revista Brasileira de Ciência do Solo, 29:287-295.

Santos ML, Carvalho MP, Rapassi RMA, Muraishi CT, Maller A \& Matos FA (2006) Correlação linear e espacial entre produtividade de milho (Zea mays - L.) e atributos físicos de um Latossolo Vermelho distroférrico sob plantio direto do Cerrado Brasileiro. Acta Scientiarum, 3:313-321.

Schaffrath VR, Tormena CA, Fidalski J \& Gonçalves ACA (2008) Variabilidade e correlação espacial de propriedades físicas de solo sob plantio direto e preparo convencional. Revista Brasileira de Ciência do Solo, 32:1369-1377.

Schlotzhaver SD \& Littlel RC (1997) SAS system for elementary statistical analysis. 2a ed. Cary, SAS. 441p.

Rev. Ceres, Viçosa, v. 59, n.1, p. 125-135, jan/fev, 2012 
Souza ZM, Marques Júnior J, Pereira GT \& Bento MJC (2004) Variabilidade espacial de atributos físicos de um Latossolo Vermelho sob cultivo de cana-de-açúcar. Revista Brasileira de Engenharia Agrícola Ambiental, 8:51-58.

Spiegel MR (1985) Estatística. 2a ed. São Paulo, McGraw-Hill do Brasil. 81p.

Stolf R (1991) Teoria e teste experimental de fórmulas de transformação dos dados de penetrômetro de impacto em resistências do solo. Revista Brasileira de Ciência do Solo, 15:229-235.
UNESP/Universidade Estadual Paulista. Faculdade de Engenharia. Departamento de Fitossanidade, Engenharia Rural e Solos. Área de Hidráulica e Irrigação. Dados agrometeorológicos. Disponível em: http://www.agr.feis.unesp.br/clima.php. Acessado em: 16 de dezembro de 2011.

Vieira SR, Castro OM, Maria IC (1989) Dinâmica da água no solo em função do manejo. In: Plantio direto no Estado de São Paulo, Assis. Plantio direto no Estado de São Paulo, Piracicaba, FEALQ. p.103-126. 